\title{
Article \\ Surgical Management for Dystonia: Efficacy of Deep Brain Stimulation in the Long Term
}

\author{
Walaa A. Kamel ${ }^{1,2}{ }^{\oplus}$, Pritam Majumdar ${ }^{3, *}$, Georgios Matis ${ }^{3}\left(\mathbb{D}\right.$, Albert J. Fenoy ${ }^{4}$, Shankar Balakrishnan ${ }^{5}$, \\ Ali T. Zirh ${ }^{6}$, Aslihan Cevik ${ }^{7}$, Amit Kumar Tomar ${ }^{8}$ and Naoufel Ouerchefani ${ }^{9}$ \\ 1 Neurology Department, Faculty of Medicine, Beni-Suef University, Beni-Suef 6251, Egypt; \\ walaaneuro@yahoo.com \\ 2 Neurology Department, Ibn-Sina Hospital, Kuwait City 25427, Kuwait \\ 3 Department of Stereotactic and Functional Neurosurgery, University Cologne Hospital, \\ 50931 Cologne, Germany; georgios.matis@uk-koeln.de \\ 4 Department of Neurosurgery, McGovern Medical School, The University of Texas at Houston, \\ UTHealth Neurosciences, Houston, TX 77030, USA; Albert.J.Fenoy@uth.tmc.edu \\ 5 Department of Neurology and Neuromodulation, MIOT International Hospital, Hennai 600089, India; \\ dr.shankar.dm@gmail.com \\ 6 Department of Neurosurgery, Istanbul Medipol University, Istanbul 34810, Turkey; ali@alizirh.com \\ 7 Department of Neurosurgery, Istanbul Aydin University, Istanbul Medical Park Florya, \\ Istanbul 34295, Turkey; aslihancevik@gmail.com \\ 8 Department of Anesthesia and Neurosurgery, Indo-Gulf Hospital, Noida 201301, India; \\ dramittomar@gmail.com \\ 9 Department of Neurosurgery, Foch Hospital, 92150 Paris, France; n.ouerchefani@hopital-foch.com \\ * Correspondence: drx.pritam@gmail.com
}

Citation: Kamel, W.A.; Majumdar, P.; Matis, G.; Fenoy, A.J.; Balakrishnan,

S.; Zirh, A.T.; Cevik, A.; Tomar, A.K.; Ouerchefani, N. Surgical

Management for Dystonia: Efficacy of Deep Brain Stimulation in the Long Term. Neurol. Int. 2021, 13, 371-386. https://doi.org/10.3390/

neurolint13030037

Academic Editor: Tibor Hortobagyi

Received: 9 June 2021

Accepted: 25 July 2021

Published: 2 August 2021

Publisher's Note: MDPI stays neutral with regard to jurisdictional claims in published maps and institutional affiliations.

Copyright: (c) 2021 by the authors. Licensee MDPI, Basel, Switzerland. This article is an open access article distributed under the terms and conditions of the Creative Commons Attribution (CC BY) license (https:/ / creativecommons.org/licenses/by/ $4.0 /)$.

\begin{abstract}
Introduction: Dystonia is a movement disorder substantially affecting the quality of life. Botulinum Neurotoxin (BoNT) is used intramuscularly as a treatment for dystonia; however, not all dystonia patients respond to this treatment. Deep brain stimulation (DBS) is an established treatment for Parkinson's disease (PD) and essential tremor, but it can help in dystonia as well. Objectives: We studied a total of 67 dystonia patients who were treated with DBS over a period of 7 years to find out the long-term efficacy of DBS in those patients. First, we calculated patient improvement in post-surgery follow-up programs using the Global Dystonia Severity scale (GDS) and Burke-Fahn-Marsden dystonia rating scale (BFMDRS). Secondly, we analyzed the scales scores to see if there was any statistical significance. Methods: In our study we analyzed patients with ages from 38 to 78 years with dystonia who underwent DBS surgery between January 2014 and December 2020 in four different centers (India, Kuwait, Egypt, and Turkey). The motor response to DBS surgery was retrospectively measured for each patient during every follow-up visit using the GDS and the BFMDRS scales. Results: Five to 7 years post-DBS, the mean reduction in the GDS score was $30 \pm 1.0$ and for the BFMDRS score $26 \pm 1.0$. The longitudinal change in scores at 12 and 24 months post-op was also significant with mean reductions in GDS and BFMDRS scores of $68 \pm 1.0$ and $56 \pm 1.0$, respectively. The $p$-values were $<0.05$ for our post-DBS dystonia patients. Conclusions: This study illustrates DBS is an established, effective treatment option for patients with different dystonias, such as generalized, cervical, and various brain pathology-induced dystonias. Although symptoms are not completely eliminated, continuous improvements are noticed throughout the post-stimulation time frame.
\end{abstract}

Keywords: deep brain stimulation (DBS); GLOBAL DYSTONIA SEVERITY scale (GDS); Burke-FahnMarsden dystonia rating scale (BFMDRS); subthalamic nucleus (STN); globus pallidus interna (GPi)

\section{Introduction}

Dystonia is the third most common movement disorder after essential tremor and Parkinson's disease (PD). Dystonia is normally considered a heterogeneous group of disor- 
ders characterized by abnormal muscle contractions leading to abnormal body posture [1]. Recently, the International Movement Disorders Society (MDS) proposed new classifications and approaches that can help to differentiate dystonia and its subgroups. According to MDS classifications, group I describes the clinical characteristics of the disease based on the patient's age of onset, body distribution (focal, segmental, generalized), temporal pattern (persistent, action induced, paroxysmal), and associated with other features such combined or isolated symptoms. On the contrary, group II describes the etiology of the disorders such as inherited or acquired, and also with clinical evidence such as brain injuries or genetic causes [1,2]. These classifications help to avoid previous terming of primary or secondary dystonias where clinicians would provide an etiological diagnosis for patients that remain unclear despite extensive workups for new genetic etiologies [2]. In the past, clinicians were afraid of performing DBS surgeries on so-called secondary or "non-primary" dystonias because they believed that the success rate in these diagnoses was much lower. Currently, there are few medications available for treatment of dystonia symptoms [2]. However, treatment with BoNT does not incur responses in all dystonia patients [3]. For generalized dystonia patients, pharmacotherapies are very limited with higher occurrences of drug-induced side effects [4]. DBS surgery is now approved by CE mark in Europe and by the Food and Drug Administration (FDA) under a humanitarian device exemption (HDE) in the US [4,5]. In 1950, Hess and Hassler performed the first brain stimulation experiments in globus pallidus interna (GPi) on animal models to identify the responses on muscles contractions and postures. Based on their studies, they demonstrated that electrical stimulation in the GPi showed better responses for controlling body postures than stimulation in the thalamic regions and various basal ganglia structures [6-8]. In the late 1990s, DBS surgery became very popular after Professor Alim Louis Benabid's discovery of subthalamic nucleus (STN) DBS for targeting of PD [9,10]. At the same time, pallidal DBS also became popular for dystonia, and the GPi became the area of interest for targeting in DBS surgery [11-13]. A few years later, Sanghera et al. compared his hypothesis in their study with 15 patients with dystonia and 78 patients with PD [14-16]. They reported that GPe and GPi neurons displayed similar discharge rates and discharge patterns in dystonia to that of $\mathrm{PD}$, but firing neurons were significantly lower than those in PD patients. Although most of the patients in their study were under general anesthesia, it overall appeared that discharge rates of GPi neurons were not affected. Later on, Hutchison et al. examined GPi neuronal firing under local anesthesia for 7 out of 11 patients in their study and showed that for those 7 patients GPi neuronal firing was similar to other PD patients. They concluded that a hypoactive basal ganglia output is not a consistent feature of dystonia, and that anesthesia may have a marked influence on basal ganglia firing rates and patterns [16-18].

In this study, our objective was to evaluate our various dystonia patients' improvements over 1 to 7 years post-DBS in GPi and highlight the importance of proper DBS programming patterns for long-lasting patient improvements.

\section{Methods}

\subsection{Study Subjects}

We analyzed a total of 67 patients with dystonia aged between 38 to 78 years coming from four centers (India, Kuwait, Egypt, and Turkey). Our patient recruitment numbers (from January 2014 to December 2020) are shown in Table 1. Table 2 presents the different diagnoses according to the MDS dystonia rating scale before DBS. Table 3 illustrates the quality of life of these patients before DBS. 
Table 1. Total numbers of patients that underwent bilateral GPi DBS surgery for dystonia at four centers.

\begin{tabular}{ccc}
\hline Year of the Surgery & Total Number of Patients & Placements of the Electrodes \\
\hline January 2014 to December 2014 & 10 (7 males and 3 females $)$ & Bilateral GPi \\
January 2015 to December 2015 & 9 (5 males and 4 females $)$ & Bilateral GPi \\
January 2016 to December 2016 & 11 (6 males and 5 females $)$ & Bilateral GPi \\
January 2017 to December 2017 & 7 (2 males and 5 females $)$ & Bilateral GPi \\
January 2018-December 2018 & 9 (7 males and 2 females $)$ & Bilateral GPi \\
January 2019 to December 2019 & 12 (10 males and 2 females $)$ & Bilateral GPi \\
January 2020 to December 2020 & 9 (5 males and 4 females $)$ & \\
\hline
\end{tabular}

Table 2. Diagnosis of the dystonia patients according to the MDS GDS scaling.

\begin{tabular}{cc}
\hline Diagnosis & Total Number of Patients \\
\hline Generalized Dystonia & 30 (20 patients DYT-1 positive and 10 patients DYT-3) \\
CERVICAL DYSTONIA & 27 (17 patients DYT-5 positive and 10 patients DYT-6) \\
Blepharospasm with PISA syndrome associated with & 5 \\
Parkinson's disease & 5 \\
Post-stroke Hemi Dystonia & 5 \\
\hline
\end{tabular}

Table 3. Quality of life of dystonia patients before DBS surgery.

\begin{tabular}{cc}
\hline Quality of Life with Dystonia & Total Number of Patients with Dystonia \\
\hline Completely dependent and wheelchair bound & 20 \\
Partially able to do social things with dependency & 30 \\
Completely independent with dystonia & 17 \\
\hline
\end{tabular}

This study was designed to analyze the long-term efficacy of DBS surgery in dystonia patients and was approved by all institutional ethical committees.

\subsection{Global Dystonia Severity Scale (GDS) and Burke-Fahn-Marsden Dystonia Rating Scale (BFMDRS) Evaluation}

The motor responses to the DBS surgery were retrospectively measured for each patient using the GDS (total score 140) and the BFMDRS scale (total score 120); this was done before DBS surgery and 1, 3, 6, 12, 24, 36, 48, 60, 72, and 84 months post-DBS surgery during follow-up visits. We presented individual patient GDS and BFMDRS scoring as well as the $p$ value.

\subsection{Neuropsychological and Psychiatric Evaluations}

For all patients (before DBS surgery) neuropsychological evaluations were performed using the Kutcher generalized social anxiety scale (KGSAS) and the Warwick- Edinburgh Mental Well-being Scale (WEMWBS), Table 4.

Table 4. Neuropsychological assessments before DBS surgery.

\begin{tabular}{ccc}
\hline Total Number of Patients & Neuropsychological Assessment & Scale Performed \\
\hline 11 & Severe depression with total social withdrawal & WEMWBS and KGSAS \\
4 & Moderate depression with suicidal tendency & WEMWBS and KGSAS \\
1 & Severe depression with suicidal tendency & WEMWBS and KGSAS \\
51 & Minimal depression associated with dystonia & WEMWBS and KGSAS \\
\hline
\end{tabular}




\subsection{Operative Technique}

The target for dystonia is located in the posteroventral lateral GPi, and it is the same that has been used for PD. This targeting is slightly anterior to the usual pallidotomy target to avoid spreading current to the internal capsule, as occurs with higher amplitudes of stimulation, which is very important in dystonia programming [14,15]. The target is usually chosen $20 \mathrm{~mm}$ to $22 \mathrm{~mm}$ lateral to and $4 \mathrm{~mm}$ below the intercommissural line and $2-3 \mathrm{~mm}$ anterior to the intercommissural midpoint. However, various third ventricle shapes and sizes can provide misleading information in establishing a reference point as the "midline". In this context, it is better to consider the "laterality" of the target as $18 \mathrm{~mm}$ lateral to the border of the lateral ventricle $[16,17]$. MRI brain images with IR sequences are crucial to determine the brain anatomy with the targeted nucleus' (GPi or STN) proper condition; stereotactic imaging systems are necessary to identify the proper nucleus and perform the planning for the surgery $[16,17]$. In our centers, we used either the Leksell ${ }^{\circledR}$ frame (Elekta Inc., Stockholm, Sweden) or Cosman-Roberts-Well's frame (CRW; Integra Radionics, Burlington, MA, USA), where the ring is mounted on the head of the patient and a stereotactic computerized tomography (CT) was performed without contrast using a slice thickness of $1 \mathrm{~mm}$. Then, the MRI and CT images were merged, and stereotactic coordinates were obtained with the Frame link 5 software on a Stealth Station (Medtronic, Minneapolis, MN, USA). A high-resolution T1-weighted, inversion recovery (IR)-weighted (slice thickness $2 \mathrm{~mm}$ without gap) and contrast-enhanced MRI was usually obtained for better clarity of the GPi nucleus (Figures 1 and 2).
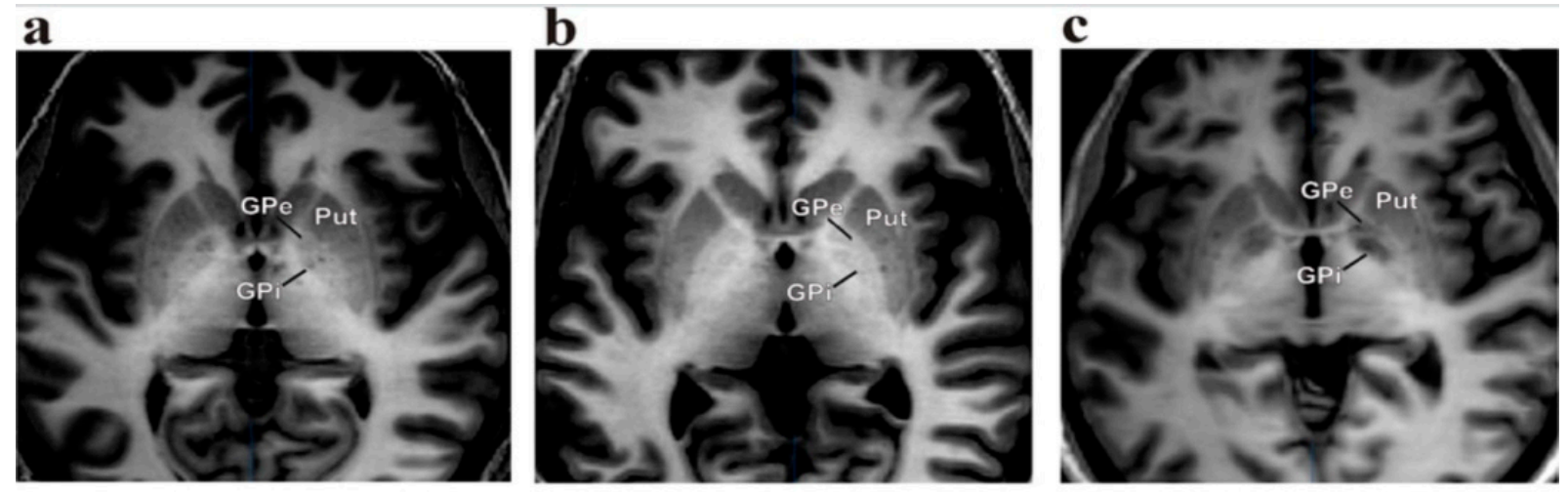

Figure 1. (a-c) A high-resolution T1-weighted, inversion recovery (IR)-weighted contrast-enhanced MRI used to obtain better clarity of the GPi nucleus with GPe and putamen.

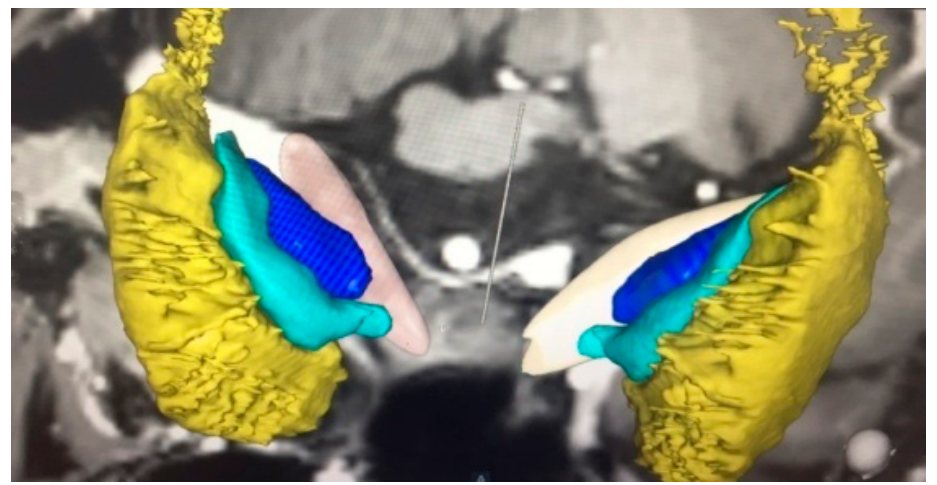

Figure 2. Graphical representation of GPi, GPe, and Putamen. Yellow portion refers Putamen, light green portion refers GPe, and dark blue portion refers GPi nucleus. (This graphical diagram was made by using Medtronic sure tune software.) 
Intraoperative macro stimulation test through the microelectrode was first performed at 1.0-4.0 V, $200 \mu \mathrm{s}$, and $130 \mathrm{~Hz}$ using trajectories and depths that revealed pallidal firing patterns, to check responses at the level of the target and below the target to find the threshold for internal capsule response. MER provides important real-time information that other localization techniques simply do not [19-22]. In GPi targeting for dystonia, extrinsic responses can come from optic tract stimulation, which results in phosphenes or the perception of flashes, and from internal capsule stimulation, which results in tonic contraction of the contralateral face or extremities [23-26]. In intrinsic responses, patients feel tightness or paresthesia. Alternatively, this same surgery is usually performed under general anesthesia for pediatric patients as well as in adults for those who have severe dystonic postures. In dystonia cases, bilateral GPi lead placement can also be done under local anesthesia or general anesthesia depending on the patient's condition and posture [27-30].

\subsection{Post-Operative DBS Programming}

The improvement of dystonia in pallidal stimulation could be delayed, and it can take several months to get a response. In our experience, phasic dystonic movements respond early to stimulation, whereas tonic components take several weeks to respond well in post-surgery stimulation. All patients had a preoperative brain MRI to calculate the electrode trajectory and target. Post-operatively, the correct electrode positioning was confirmed by computer tomography in all patients and evaluated by the operating neurosurgeon in each center. As long as the initial programming settings are involved, two different patterns were applied. One group of patients (32 patients) initially had bipolar configurations, using the 1 st most ventral contact as negative and 2 nd most ventral contact as positive with 210 microseconds ( $\mu$ s) pulse width and $130 \mathrm{~Hz}$ frequency. The amplitude initially was kept between $2.0 \mathrm{~V}$ to $3.0 \mathrm{~V}$ depending on the patient's responses post-surgery before discharge. The second group of patients (35 patients) had a monopolar configuration pattern of programming where IPG was kept as positive and the 2nd most ventral contact was kept negative with pulse width of 90 microseconds ( $\mu \mathrm{s})$, frequency $150 \mathrm{~Hz}$, and amplitude varied between 2 and $4 \mathrm{~V}$. In both groups of patients, stimulation parameters gradually increased over a period of 3 months after hospital discharge.

\subsection{Statistical Analysis}

Due to non-normal data distribution, a Mann-Whitney $U$ test was used to compare continuous independent factors including generator parameter values, GDS, and BFMDRS scores between groups. Spearman correlation coefficient was used for correlation analyses between generator life and generator pulses. Bonferroni correction was used to account for multiple comparisons. $p<0.05$ was considered statistically significant. The statistical analyses were done using SPSS versions 24.0 (SPSS Inc., Chicago, IL, USA).

\section{Results}

\subsection{Post-Operative 2014 Batch of 10 Patients' Improvement (3 Months to 84 Months Post-DBS)}

Post-operatively, we started the clinical evaluations systematically using GDS and BFMDRS scores for the first 10 patients who underwent DBS surgery in the year of 2014. Significant improvement was seen between the preoperative state and 84 months poststimulation. The GDS $p$-value was 0.017 after 84 months post-DBS stimulation, which showed improvement of more than $86 \%$ for those patients, and the BFMDRS $p$-value was 0.022 after 84 months. Detailed GDS and BFMDRS scorings were calculated and described in Figure 3A,B. Full details of GDS and BFMDRS scoring are shown in Table 5. 
Table 5. Full details of GDS and BFMDRS scoring before and after DBS.

\begin{tabular}{|c|c|c|c|c|c|c|c|c|c|}
\hline $\begin{array}{l}\text { Patients No. } \\
\text { (Total Patients } \\
\text { No. = 67) }\end{array}$ & $\begin{array}{c}\text { Year } \\
\text { DBS } \\
\text { Undergone }\end{array}$ & Sex & Age & Dystonia Types & $\begin{array}{l}\text { GDS Base Score } \\
\text { before DBS }\end{array}$ & $\begin{array}{c}\text { BFMDRS Base } \\
\text { Score before DBS }\end{array}$ & $\begin{array}{c}\text { GDS Base } \\
\text { Score after DBS }\end{array}$ & $\begin{array}{l}\text { BFMDRS Base } \\
\text { Score after DBS }\end{array}$ & $\begin{array}{l}\text { Post DBS Total Timeline } \\
\text { (GDS and BFMDRS } \\
\text { Scaling Done Post DBS) }\end{array}$ \\
\hline $\mathrm{P} 1$ & 2014 & M & 44 & Generalized & $118 / 140$ & $98 / 140$ & $36 / 140$ & $24 / 120$ & 84 months \\
\hline P3 & 2014 & $\mathrm{~F}$ & 48 & Generalized & $129 / 140$ & $110 / 120$ & $39 / 140$ & $29 / 120$ & 84 months \\
\hline P4 & 2014 & $\mathrm{M}$ & 39 & Generalized & $106 / 140$ & $106 / 120$ & $24 / 140$ & $25 / 120$ & 84 months \\
\hline P5 & 2014 & $\mathrm{M}$ & 53 & Generalized & $131 / 140$ & $111 / 120$ & $34 / 140$ & $24 / 120$ & 84 months \\
\hline P6 & 2014 & $\mathrm{~F}$ & 65 & Generalized & $103 / 140$ & $103 / 120$ & $38 / 140$ & $28 / 120$ & 84 months \\
\hline P8 & 2014 & M & 67 & Cervical & $99 / 140$ & $102 / 120$ & $21 / 140$ & $31 / 120$ & 84 months \\
\hline P9 & 2014 & M & 78 & Cervical & $126 / 140$ & $101 / 120$ & $18 / 140$ & $29 / 120$ & 84 months \\
\hline P10 & 2014 & M & 70 & Cervical & $110 / 140$ & $95 / 120$ & $23 / 140$ & $19 / 120$ & 84 months \\
\hline P1 & 2015 & $\mathrm{M}$ & 68 & Generalized & $108 / 140$ & $108 / 120$ & $32 / 140$ & $34 / 120$ & 72 months \\
\hline P2 & 2015 & $\mathrm{~F}$ & 55 & Generalized & $105 / 140$ & $95 / 120$ & $33 / 140$ & $31 / 120$ & 72 months \\
\hline P3 & 2015 & $\mathrm{~F}$ & 48 & Generalized & $120 / 140$ & $105 / 120$ & $39 / 140$ & $39 / 120$ & 72 months \\
\hline $\mathrm{P} 4$ & 2015 & $\mathrm{M}$ & 38 & Generalized & $106 / 140$ & $106 / 120$ & $25 / 140$ & $35 / 120$ & 72 months \\
\hline P5 & 2015 & $\mathrm{M}$ & 41 & Cervical & $121 / 140$ & $101 / 120$ & $34 / 140$ & $34 / 120$ & 72 months \\
\hline P6 & 2015 & $\mathrm{M}$ & 70 & Cervical & $103 / 140$ & $103 / 120$ & $31 / 140$ & $28 / 120$ & 72 months \\
\hline P8 & 2015 & $\mathrm{~F}$ & 61 & Cervical & $109 / 140$ & $102 / 120$ & $21 / 140$ & $31 / 120$ & 72 months \\
\hline P9 & 2015 & M & 40 & Generalized & $116 / 140$ & $101 / 120$ & $19 / 140$ & $29 / 120$ & 72 months \\
\hline $\mathrm{P} 1$ & 2016 & M & 70 & Generalized & $108 / 140$ & $108 / 120$ & $32 / 140$ & $34 / 120$ & 60 months \\
\hline P2 & 2016 & $\mathrm{M}$ & 67 & $\begin{array}{l}\text { Post Stroke } \\
\text { Hemi dystonia }\end{array}$ & $105 / 140$ & $95 / 120$ & $33 / 140$ & $31 / 120$ & 60 months \\
\hline P3 & 2016 & M & 53 & Generalized & $120 / 140$ & $105 / 120$ & $39 / 140$ & $39 / 120$ & 60 months \\
\hline $\mathrm{P} 4$ & 2016 & $\mathrm{~F}$ & 46 & Generalized & $106 / 140$ & $106 / 120$ & $25 / 140$ & $35 / 120$ & 60 months \\
\hline P5 & 2016 & $\mathrm{M}$ & 58 & $\begin{array}{c}\text { Generalized } \\
\text { Blepharospasm }\end{array}$ & $121 / 140$ & $101 / 120$ & $34 / 140$ & $34 / 120$ & 60 months \\
\hline P6 & 2016 & $\mathrm{~F}$ & 39 & $\begin{array}{l}\text { With PISA } \\
\text { syndrome }\end{array}$ & $103 / 140$ & $103 / 120$ & $31 / 140$ & $28 / 120$ & 60 months \\
\hline P7 & 2016 & $\mathrm{~F}$ & 48 & Cervical & $101 / 140$ & $101 / 120$ & $28 / 140$ & $37 / 120$ & 60 months \\
\hline P8 & 2016 & $\mathrm{M}$ & 50 & Cervical & $109 / 140$ & $102 / 120$ & $21 / 140$ & $31 / 120$ & 60 months \\
\hline P9 & 2016 & $\mathrm{~F}$ & 51 & Generalized & $116 / 140$ & $101 / 120$ & $19 / 140$ & $29 / 120$ & 60 months \\
\hline P10 & 2016 & $\mathrm{~F}$ & 65 & Generalized & $112 / 140$ & $98 / 120$ & $23 / 140$ & $32 / 120$ & 60 months \\
\hline
\end{tabular}


Table 5. Cont.

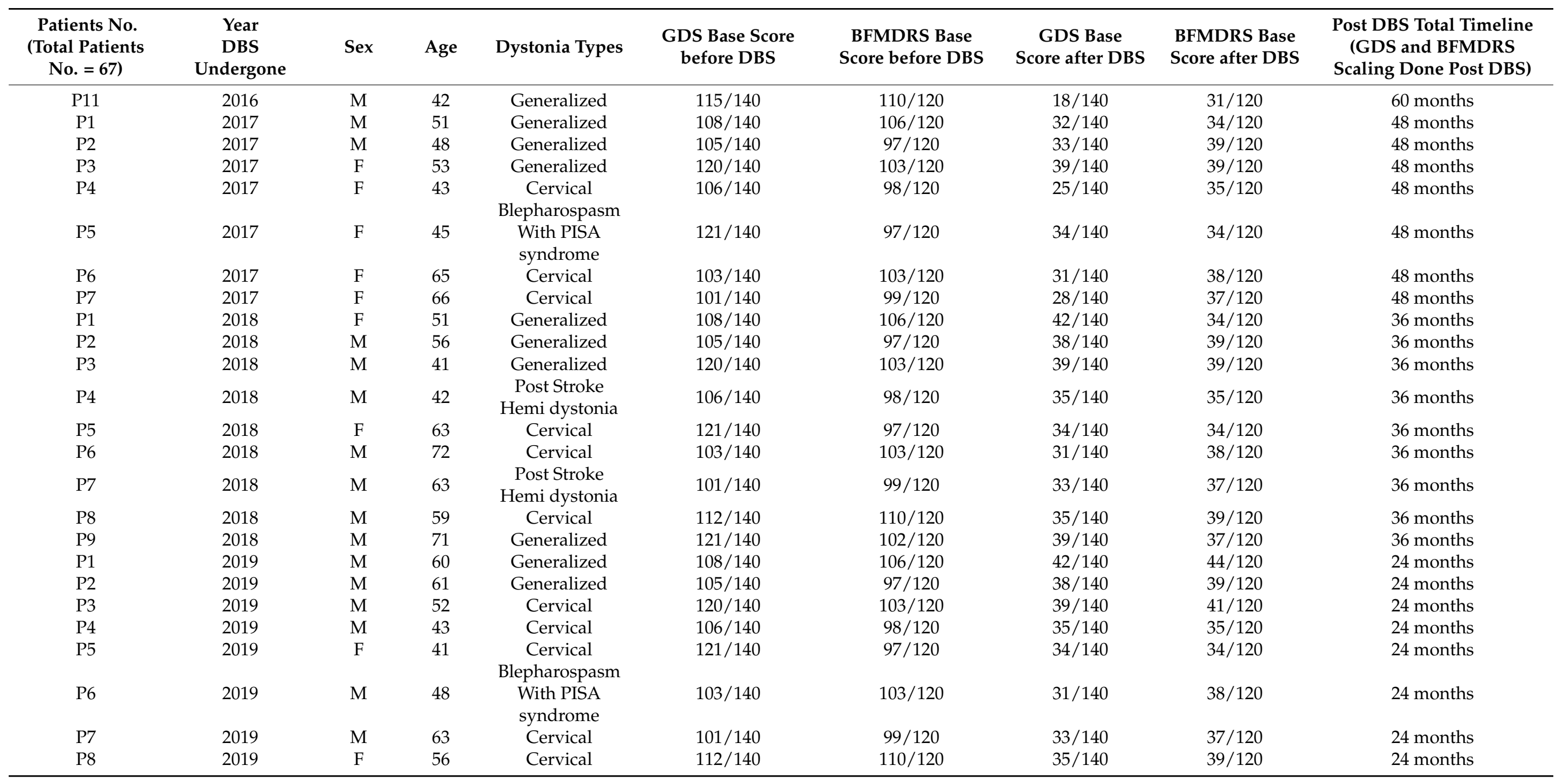


Table 5. Cont.

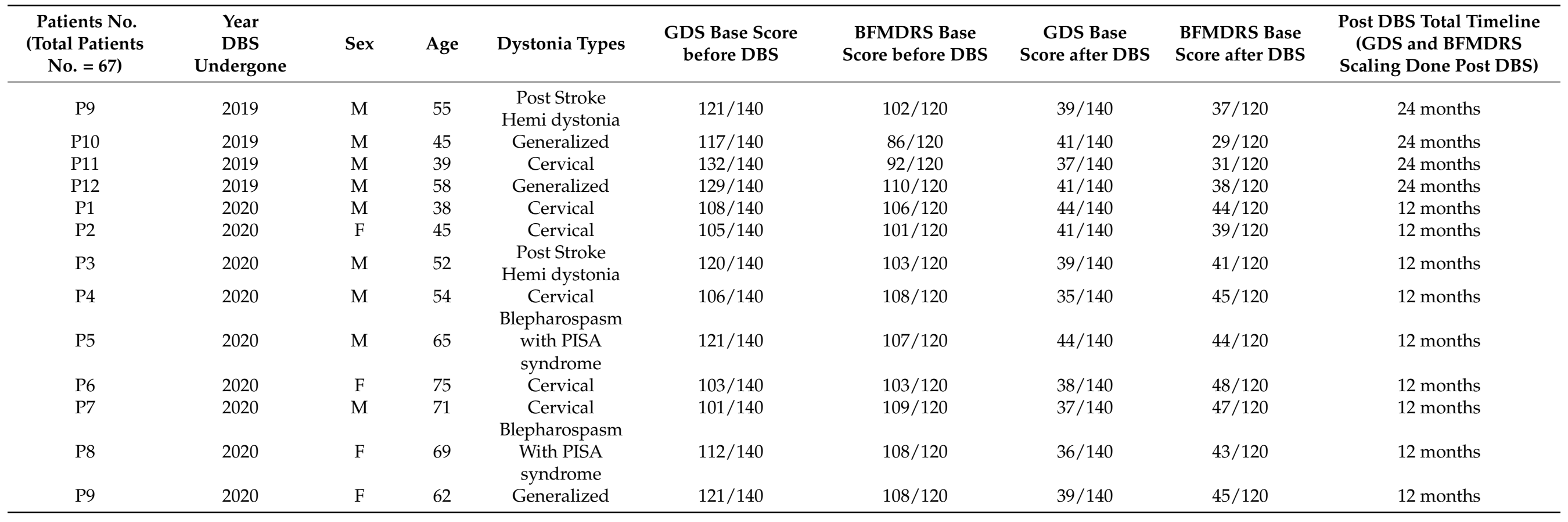




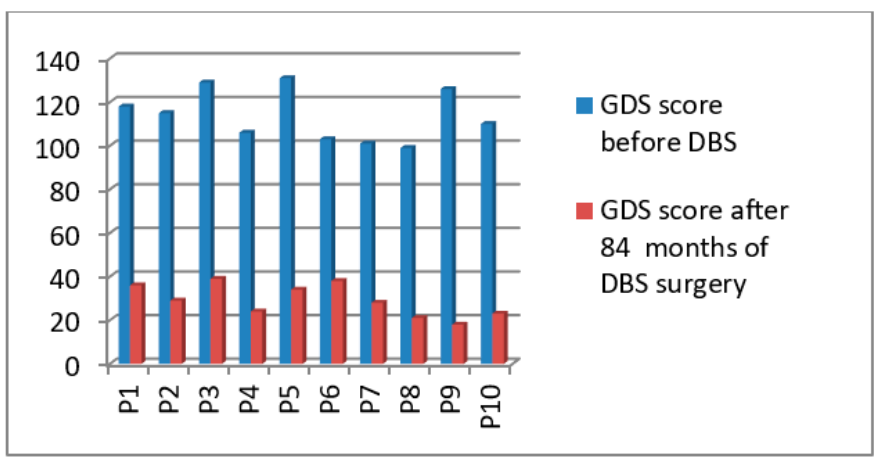

(A)

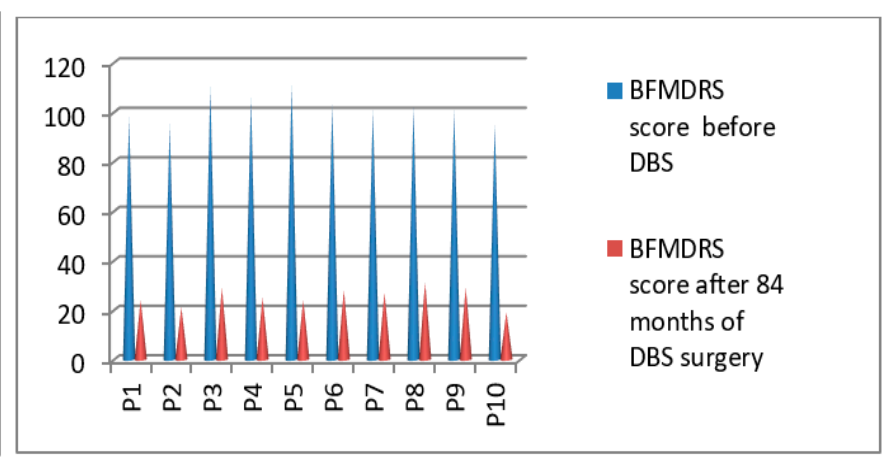

(B)

Figure 3. GDS (A) and BFMDRS (B) scores before DBS and after 84 months of DBS surgery.

\subsection{Post-Operative 2015 Batch of 9 Patients' Improvement (3 Months to 72 Months Post-DBS)}

Post-operatively we started the clinical evaluations systematically using GDS and BFMDRS scores for the second batch of 9 patients who underwent DBS surgery in the year of 2015. The GDS $p$-value was 0.021 after 72 months and the BFMDRS $p$-value was 0.028 after 72 months post-DBS stimulation (Figure 4A,B). Full details of GDS and BFMDRS scoring are shown in Table 5.

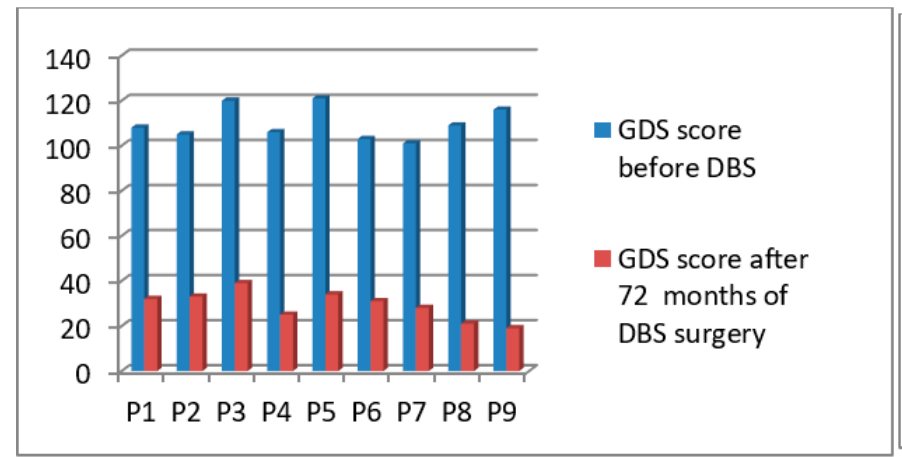

(A)

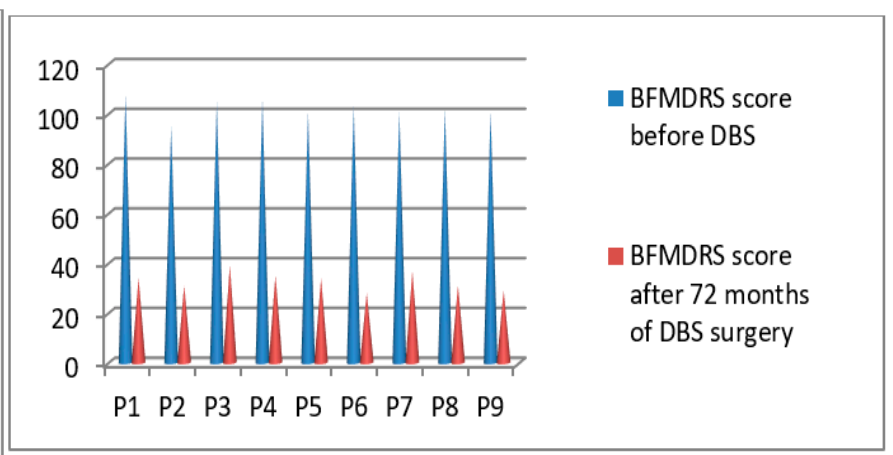

(B)

Figure 4. GDS (A) and BFMDRS (B) scores before DBS and after 72 months of DBS surgery.

\subsection{Post-Operative 2016 Batch of 11 Patients' Improvement (3 Months to 60 Months Post-DBS)}

Post-operatively, we started the clinical evaluations systematically using GDS and BFMDRS scores for the third batch of 11 patients who underwent DBS surgery in the year of 2016. The GDS $p$-value was 0.021 after 60 months and the BFMDRS $p$-value was 0.029 after 60 months post-DBS stimulation (Figure 5A,B). Full details of GDS and BFMDRS scoring are shown in Table 5. 


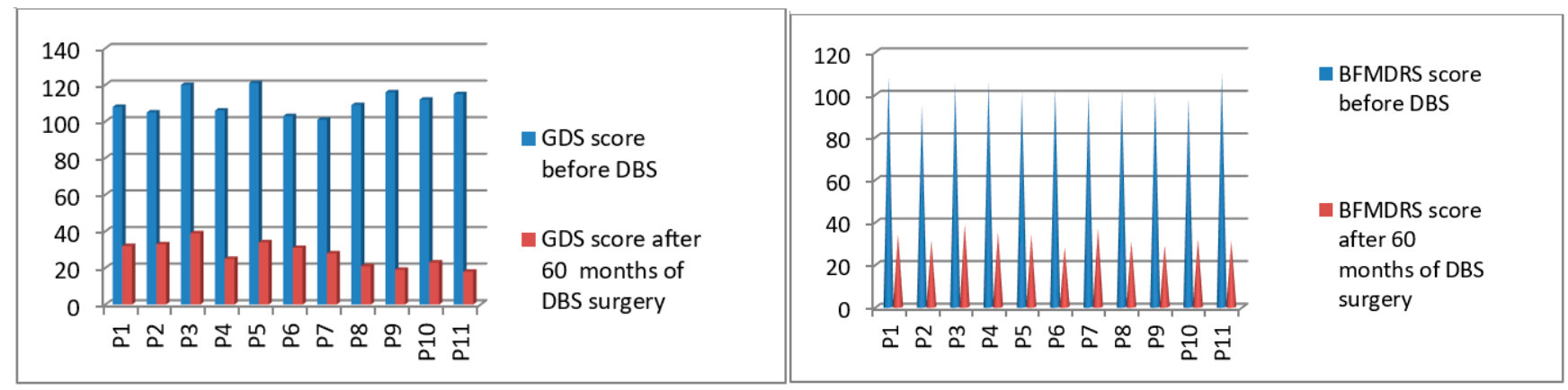

(A)

(B)

Figure 5. GDS (A) and BFMDRS (B) scores before DBS and after 60 months of DBS surgery.

3.4. Post-Operative 2017 Batch of 7 Patients' Improvement (3 Months to 48 Months Post-DBS)

Post-operatively we started the clinical evaluations systematically using GDS and BFMDRS scores for the fourth batch of 7 patients who underwent DBS surgery in the year of 2017. The GDS $p$-value was 0.039 after 48 months and the BFMDRS $p$-value was 0.044 after 48 months post-DBS stimulation (Figure 6A,B). Full details of GDS and BFMDRS scoring are shown in Table 5.

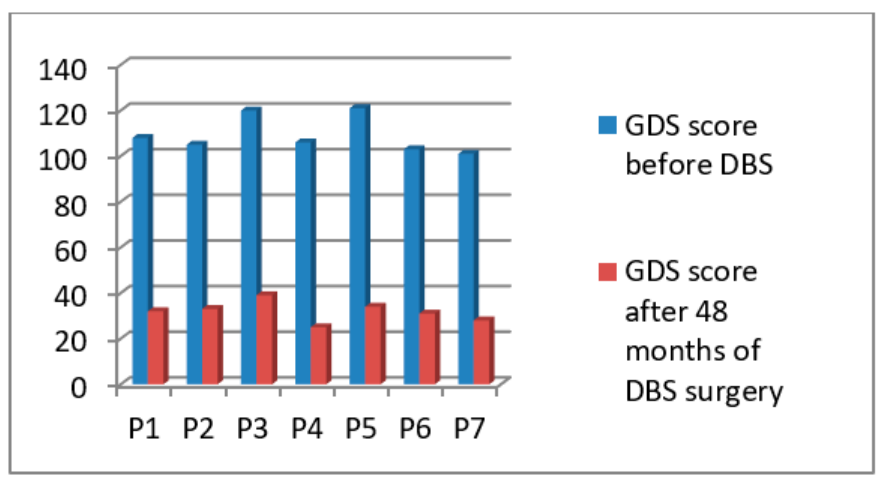

(A)

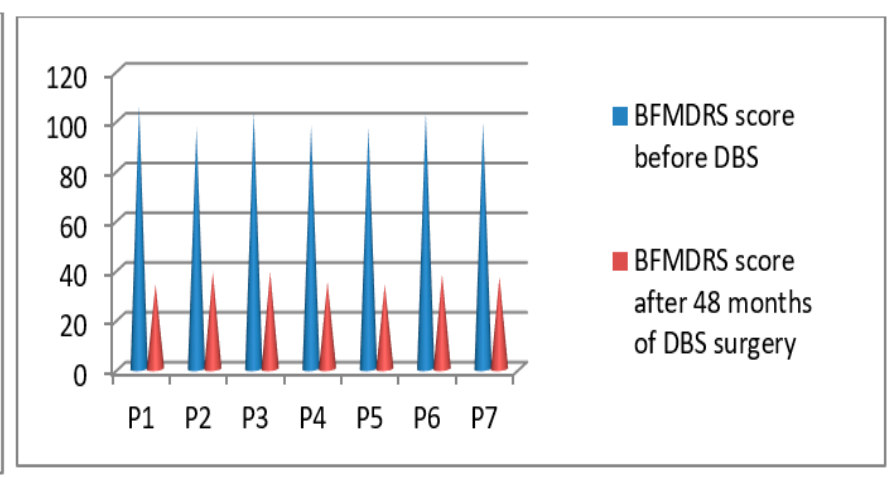

(B)

Figure 6. GDS (A) and BFMDRS (B) scores before DBS and after 48 months of DBS surgery.

3.5. Post-Operative 2018 Batch of 9 Patients' Improvement (3 Months to 36 Months Post-DBS)

Post-operatively we started the clinical evaluations systematically using GDS and BFMDRS scores for the fifth batch of 9 patients who underwent DBS surgery in the year of 2018. The GDS $p$-value was 0.042 after 36 months and the BFMDRS $p$-value was 0.042 after 36 months post-DBS stimulation (Figure 7A,B). Full details of GDS and BFMDRS scoring showed in Table 5. 


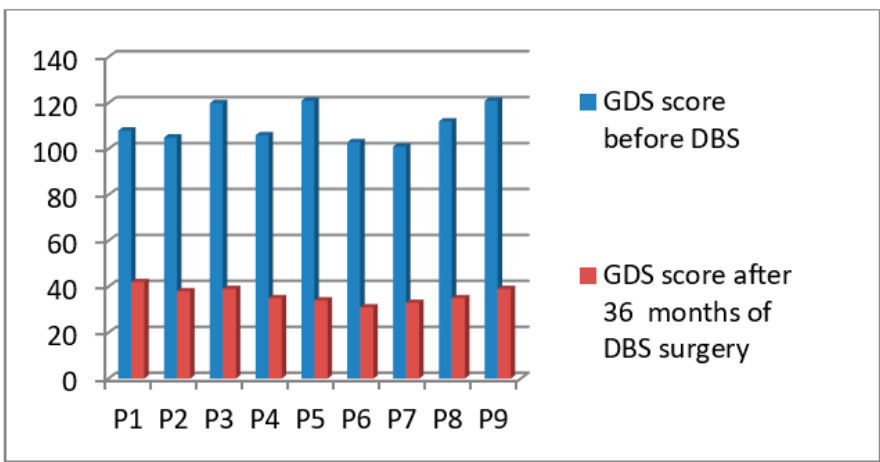

(A)

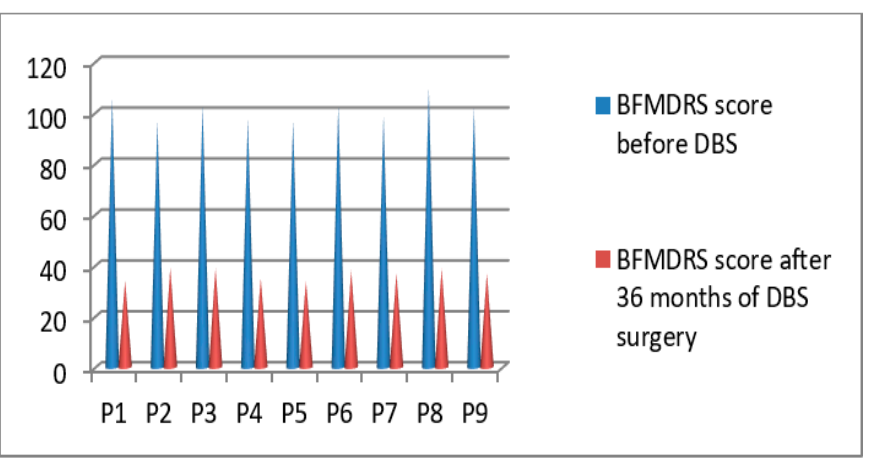

(B)

Figure 7. GDS (A) and BFMDRS (B) scores before DBS and after 36 months of DBS surgery.

3.6. Post-Operative 2019 Batch Total 12 Patients' Improvement (3 Months to 24 Months Post-DBS)

Post-operatively, we started the clinical evaluations systematically using GDS and BFMDRS scores for the sixth batch of 12 patients who underwent DBS surgery in the year of 2019. The GDS $p$-value was 0.044 after 24 months and the BFMDRS $p$-value was 0.046 after 24 months post-DBS stimulation (Figure 8A,B). Full details of GDS and BFMDRS scoring are shown in Table 5.

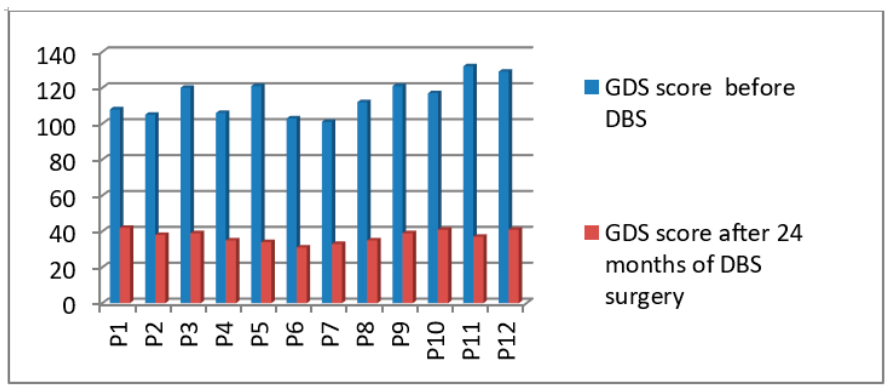

(A)

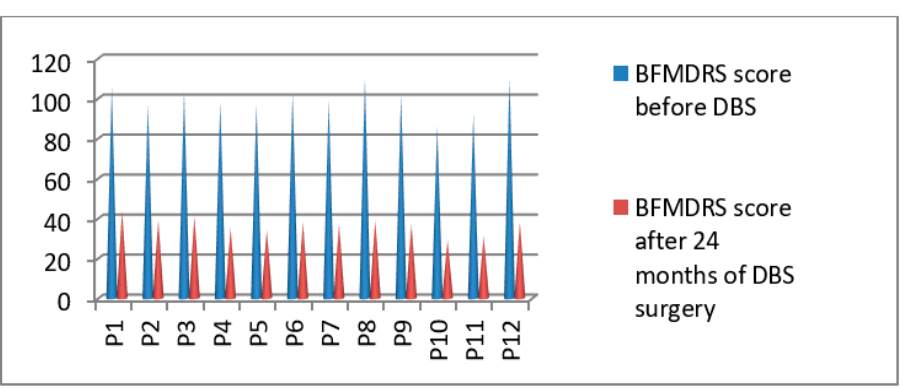

(B)

Figure 8. GDS (A) and BFMDRS (B) scores before DBS and after 24 months of DBS surgery.

3.7. Post-Operative 2020 Batch of 9 Patients' Improvement (3 Months to 16 Months Post-DBS)

Post-operatively, we started the clinical evaluations systematically using GDS and BFMDRS scores for the seventh batch of 9 patients who underwent DBS surgery in the year of 2020. The GDS $p$-value was 0.049 after 16 months and the BFMDRS $p$-value was 0.050 after 16 months post-DBS stimulation (Figure 9A,B). Full details of GDS and BFMDRS scoring showed in Table 5. 


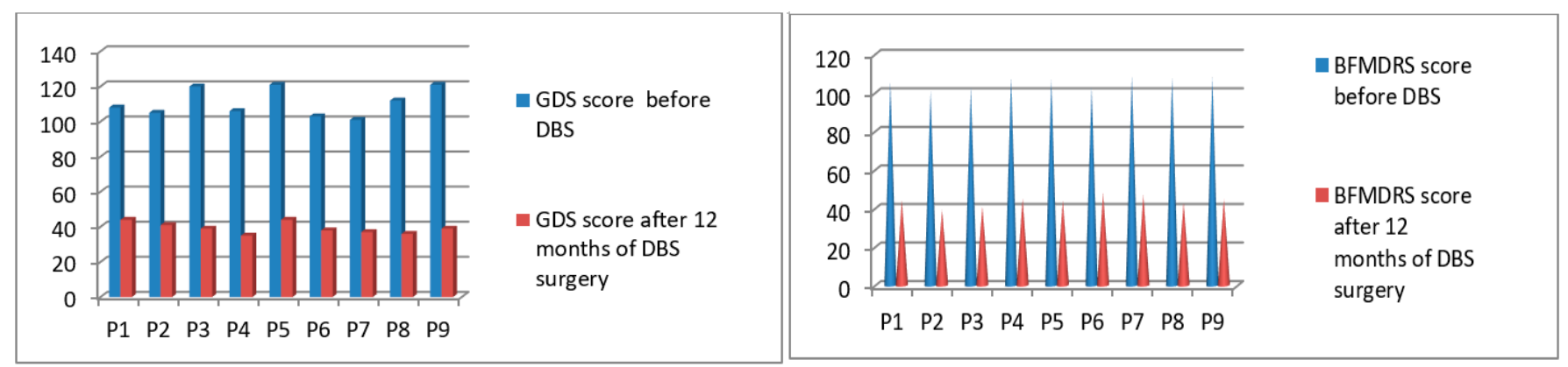

(A)

(B)

Figure 9. GDS (A) and BFMDRS (B) scores before DBS and after 12 months of DBS surgery.

\section{Discussion}

DBS has been an effective and worldwide established therapy for decades. Many articles have been published regarding the importance of DBS surgery for PD patients with demonstrated significant improvements [31-33]. However, DBS for focal, segmental, and generalized dystonia is not used as often. Few articles previously demonstrated the utility of DBS for dystonia, but the reported clinical improvement was less than what we have observed. The meta-analysis by Moro et al. showed an average BFMDRS score improvement of more than 65\%, depending on the patient's severity [34-38].

In our study, the mean BFMDRS and GDS improvement was nearly $56 \pm 1.0$ and $68 \pm 1.0$ after DBS surgery after 6 to 12 months, respectively, with the majority of patients diagnosed with generalized and cervical dystonia. However, this study majorly demonstrated that in patients with longer stimulation (more than 5 years to 7 years) the improvement was much better, and GDS and BFMDRS scores of $30 \pm 1.0$ and $26 \pm 1.0$, respectively, can be achieved. So far, no studies showed such an improvement in patients with dystonia post-DBS stimulation. None of the patients became bed-ridden post-stimulation. Some patients showed very slow improvement post-DBS. Forty out of 67 patients became more social, and 12 young patients went back to work. Five patients with depression post-DBS were continuously monitored by their psychiatrists with close medication control. Two out of 67 patients came for frequent programming settings as those patients initially showed severe dysarthria as adverse effects of stimulation. Five out of 67 patients came with post-surgery infection requiring bilateral leads revision surgery once again, and after lead revision surgery they showed consistently good improvements. Post-operatively, in 1 patient who was earlier diagnosed with depressive behavior with suicidal tendency, the symptoms worsened after the first programming and subsided after the second programming. Otherwise, 66 out of 67 patients showed continuous improvement post-surgery.

Compared to all dystonia groups, the post-stroke hemi-dystonia patients showed the maximum improvement with $75 \%$ reduction in symptoms 3 weeks post-surgery. After 3 months, these patients showed $80 \%$ improvement in symptoms with initial stimulation itself; at 6 months post-surgery, those patients that underwent second programming for higher stimulation changes showed a $90 \%$ control of the symptoms. Improvement continued after 12 months post-surgery, and follow-up visits continued. The preoperative mean GDS was $10.79 \pm 1.0$ for generalized dystonia and $11.79 \pm 1.0$ for cervical dystonia patients.

All patients had Medtronic quadripolar 3387 DBS electrode lead placements (Medtronic, Minneapolis, MN, USA), which have $1.5 \mathrm{~mm}$ gaps between the single contacts in both sides of the GPi. Forty-seven patients had Medtronic Activa RC implanted pulse generator (IPG), and 20 patients had Medtronic Activa PC IPG implanted. Twenty patients chose nonrechargeable IPGs for cost savings, and 45 patients chose rechargeable IPGs to avoid future replacement surgeries. The most common stimulation-related side effects were dysarthria, impaired upper and lower limb coordination, and impaired balance. These were transient and subsided after modifying programming settings. Stimulation variables, including the 
active contact(s), amplitude in volts, pulse width (PW) in microseconds, and frequency in hertz (Hz) and indicators of implantable pulse generator (IPG) longevity (impedance, current drain, and battery voltage) were recorded at each follow up visit. According to the existing literature, it has been suggested that the earlier the surgical intervention for dystonia, the better the outcome [39-42]. However, regarding this hypothesis, controversial results have also been published [42-44].

In our study, the duration of the disease or age did not correlate with the clinical responses of post-DBS patients. Interestingly, five patients with post-stroke hemi-dystonia had very good response, despite the fact that post-stroke DBS is considered controversial. In our study, a few patients with younger ages returned to their profession after DBS relative to older patients at the time of surgery. Our study showed no fatal side effects related to surgery or post-stimulation. Our adverse effects were not more than severe than other studies that were published before. We used various frequencies and pulse widths in programming our patients, starting at a very slow pace with each step monitored closely by neurologists. We used high pulse widths for a few patients, but we kept the amplitude on the lower side to overcome stimulation-induced side effects. Although we have observed similar post-stimulation-induced side effects as seen by Moro et al. in their study, in our study adverse effects were not as severe. The stimulation-related coordination in upper and lower limbs indicated most probably involvement of the internal capsule, which resolved after the second programming [44]. Tagliati et al., 2011, observed that the proportion of stimulation-related speech impairment was quite high at more than $35 \%$ [24]. We have seen two patients with post-stimulation speech impairments where dystonic posture was corrected in more than $45 \%$. The results of speech impairment suggested posteriorly located contact activation. When we changed the contact, speech-related problems resolved within 5-10 min. It remains a question to see if a directional lead can completely overcome current spreading posteriorly and related speech issues. Few earlier studies described utilization of higher stimulation parameters and probably stimulating more GPe area than GPi induced Parkinsonian symptoms in patients [44].

In our study we observed that 2 out of 67 dystonia patients developed severe post-DBS freezing of gait at higher amplitude, but after modifying the programming parameters all parkinsonian symptoms resolved immediately. Psychiatric or cognitive adverse events were rare, but in our study five patients had depression pre- and post-surgery. Few articles also demonstrated earlier IPG-related complications associated with infections, leads fractures, and hardware-related issues. However, in this study we did not see any complications associated with IPGs hardware or lead fractures.

\section{Conclusions}

This study demonstrates DBS as an effective treatment option for patients with different dystonia types such as generalized dystonia, cervical dystonia, and various brain pathology induced dystonias. This treatment is usually safe and well-tolerated. This study primarily demonstrates that an extensive stimulation period always gives better responses for dystonia patients. Post-DBS surgery infections can occur, so there is a need for precautions and proper hygiene maintenance after DBS surgery. Post-stimulation adverse events may occur but can be avoided if intensive programming is made as early as possible. Thus, we feel that more emphasis should be put upon increasing awareness of this DBS treatment option in severe drug-resistant dystonia patients.

Author Contributions: Research Project: Conception, W.A.K., A.J.F., G.M., P.M.; Organization, P.M.; Execution, P.M. Statistical Analysis: Design, A.J.F., P.M.; Execution, W.A.K., A.J.F., A.C., P.M.; Review and Critique, W.A.K., S.B., A.T.Z., A.C., A.K.T., N.O., G.M. Manuscript Preparation: Writing the First Draft, P.M.; Review and Critique, W.A.K., A.J.F., S.B., A.T.Z., A.K.T., N.O., G.M. All authors have read and agreed to the published version of the manuscript.

Funding: This research received no external funding. 
Institutional Review Board Statement: This study was designed to analyze the efficacy of DBS surgery in dystonia patients and was approved by all institutional ethical committees which are MIOT International Hospital review board (Protocol code: IPR-22R-2020IMH, Date: 10-07-2020), Istanbul Medipol University review board (Protocol code: IPR-22R-2020IMH, Date: 22-07-2020), Istanbul Aydin University review board (Protocol code: IPR-22R-2020IMH, Date: 15-07-2020), and on personal capacity W.A.K. (from Egypt and Kuwait) and P.M. combined the study. Protocol codes same for every institution as we followed the same rules and regulations for each and every step.

Informed Consent Statement: Patient consent forms were taken from each patient during this record and study.

Data Availability Statement: All data generated or analyzed during this study are included in this article. Further enquires can be directed to the corresponding author.

Acknowledgments: We would like to thank our individual centers where this study was performed and ethical committee members of these institutions to allow us to collect all patient records.

Conflicts of Interest: A.F. is a consultant for Medtronic, Inc. P.M. is also a consultant in one hospital in India. The authors declare no conflict of interest.

\section{References}

1. Albanese, A.; Bhatia, K.; Bressman, S.B.; DeLong, M.R.; Fahn, S.; Fung, V.S.; Hallett, M.; Jankovic, J.; Jinnah, H.A.; Klein, C.; et al. Phenomenology and classification of dystonia: A consensus update. Mov. Disord. 2013, 28, 863-873. [CrossRef] [PubMed]

2. Page, N.; Butler, A.; Jahanshahi, M. Quality of life in focal, segmental, and generalized dystonia. Mov. Disord. 2007, 22, 341-347. [CrossRef]

3. Ramirez-Castaneda, J.; Jankovic, J. Long-term efficacy and safety of botulinumtoxin injections in dystonia. Toxins 2013, 5, 249-266. [CrossRef] [PubMed]

4. Termsarasab, P.; Thammongkolchai, T.; Frucht, S.J. Medical treatment of dystonia. J. Clin. Mov. Disord. 2016, 3, 19. [CrossRef]

5. Volkmann, J.; Mueller, J.; Deuschl, G.; Kühn, A.A.; Krauss, J.K.; Poewe, W.; Timmermann, L.; Falk, D.; Kupsch, A.; Kivi, A.; et al. Pallidal neurostimulation in patients with medication-refractory cervical dystonia: A randomised, sham-controlled trial. Lancet Neurol. 2014, 13, 875-884. [CrossRef]

6. Mueller, J.; Skogseid, I.M.; Benecke, R.; Kupsch, A.; Trottenberg, T.; Poewe, W.; Schneider, G.H.; Eisner, W.; Wolters, A.; Müller, J.; et al. Pallidal deep brain stimulation improves quality of life in segmental and generalized dystonia: Results from a prospective, randomized sham-controlled trial. Mov. Disord. 2008, 23, 131-134. [CrossRef]

7. Halbig, T.D.; Gruber, D.; Kopp, U.A.; Schneider, G.H.; Trottenberg, T.; Kupsch, A. Pallidal stimulation in dystonia: Effects on cognition, mood, and quality of life. J. Neurol. Neurosurg. Psychiatry 2005, 76, 1713-1716. [CrossRef] [PubMed]

8. Volkmann, J.; Wolters, A.; Kupsch, A.; Müller, J.; Kühn, A.A.; Schneider, G.-H.; Poewe, W.; Hering, S.; Eisner, W.; Müller, J.-U.; et al . Pallidal deep brain stimulation in patients with primary generalised or segmental dystonia: 5-year follow-up of a randomised trial. Lancet Neurol. 2012, 11, 1029-1038. [CrossRef]

9. Valldeoriola, F.; Regidor, I.; Mínguez-Castellanos, A.; Lezcano, E.; Ruiz, P.J.G.; Rojo, A.; Salvador, A.; Castro, A.; Grandas, F.; Kulisevsky, J.; et al. Efficacy and safety of pallidal stimulation in primary dystonia: Results of the Spanish multicentric study. J. Neurol. Neurosurg. Psychiatry 2009, 81, 65-69. [CrossRef]

10. Albanese, A.; Barnes, M.P.; Bhatia, K.P.; Fernandez-Alvarez, E.; Filippini, G.; Gasser, T.; Newton, K.A.; Rektor, I.; Savoiardo, M.; Valls-Sole, J. A systematic review on the diagnosis and treatment of primary(idiopathic) dystonia and dystonia plus syndromes: Report of an EFNS/ MDS-ES task force. Eur. J. Neurol. 2006, 13, 433-444. [CrossRef]

11. Albanese, A.; Asmus, F.; Bhatia, K.; Elia, A.E.; Elibol, B.; Filippini, G.; Gasser, T.; Krauss, J.K.; Nardocci, N.; Newton, A.; et al. EFNS guidelines on diagnosis and treatment of primary dystonias. Eur. J. Neurol. 2010, 18, 5-18. [CrossRef]

12. Comella, C.L.; Leurgans, S.; Wuu, J.; Stebbins, G.T.; Chmura, T. The Dystonia Study Group Rating scales for dystonia: A multicenter assessment. Mov. Disord. 2003, 18, 303-312. [CrossRef] [PubMed]

13. Moro, E.; LeReun, C.; Krauss, J.K.; Albanese, A.; Lin, J.-P.; Autiero, S.W.; Brionne, T.C.; Vidailhet, M. Efficacy of pallidal stimulation in isolated dystonia: A systematic review and meta-analysis. Eur. J. Neurol. 2017, 24, 552-560. [CrossRef]

14. Walsh, R.A.; Sidiropoulos, C.; Lozano, A.; Hodaie, M.; Poon, Y.-Y.; Fallis, M.; Moro, E. Bilateral pallidal stimulation in cervical dystonia: Blinded evidence of benefit beyond 5 years. Brain 2013, 136, 761-769. [CrossRef] [PubMed]

15. Loher, T.J.; Capelle, H.-H.; Kaelin-Lang, A.; Weber, S.; Weigel, R.; Burgunder, J.M.; Krauss, J.K. Deep brain stimulation for dystonia: Outcome at long-term follow-up. J. Neurol. 2008, 255, 881-884. [CrossRef]

16. Panov, F.; Gologorsky, Y.; Connors, G.; Tagliati, M.; Miravite, J.; Alterman, R.L. Deep brain stimulation in DYT1 dystonia: A 10-year experience. Neurosurgery 2013, 73, 93. [CrossRef]

17. Vidailhet, M.; Vercueil, L.; Houeto, J.-L.; Krystkowiak, P.; Lagrange, C.; Yelnik, J.; Bardinet, E.; Benabid, A.-L.; Navarro, S.; Dormont, D.; et al. Bilateral, pallidal, deep-brain stimulation in primary generalised dystonia: A prospective 3 year follow-up study. Lancet Neurol. 2007, 6, 223-229. [CrossRef] 
18. Bronte-Stewart, H.; Taira, T.; Valldeoriola, F.; Merello, M.; Marks, W.J.; Albanese, A.; Bressman, S.; Moro, A.E. Inclusion and exclusion criteria for DBS in dystonia. Mov. Disord. 2011, 26, S5-S16. [CrossRef]

19. Isaias, I.U.; Alterman, R.L.; Tagliati, M. Outcome predictors of pallidal stimulation in patients with primary dystonia: The role of disease duration. Brain 2008, 131, 1895-1902. [CrossRef] [PubMed]

20. Witt, J.; Starr, P.A.; Ostrem, J.L. Use of pallidal deep brain stimulation in post infarct hemidystonia. Stereotact. Funct. Neurosurg. 2013, 91, 243-247. [CrossRef]

21. Jitkritsadakul, O.; Bhidayasiri, R.; Kalia, S.K.; Hodaie, M.; Lozano, A.M.; Fasano, A. Systematic review of hardware-related complications of deep brain stimulation: Do new indications pose an increased risk. Brain Stimul. 2017, 10, 967-976. [CrossRef]

22. Yianni, J.; Nandi, D.; Shad, A.; Bain, P.; Gregory, R.; Aziz, T. Increased risk of lead fracture and migration in dystonia compared with other movement disorders following deep brain stimulation. J. Clin. Neurosci. 2004, 11, 243-245. [CrossRef] [PubMed]

23. Oh, M.Y.; Abosch, A.; Kim, S.H.; Lang, A.E.; Lozano, A.M. Long-term hardware related complications of deep brain stimulation. Neurosurgery 2002, 50, 6.

24. Tagliati, M.; Krack, P.; Volkmann, J.; Aziz, T.; Krauss, J.K.; Kupsch, A.; Vidailhet, A.M. Long-Term management of DBS in dystonia: Response to stimulation, adverse events, battery changes, and special considerations. Mov. Disord. 2011, 26, S54-S62. [CrossRef] [PubMed]

25. Pauls, K.; Bröckelmann, P.; Hammesfahr, S.; Becker, J.; Hellerbach, A.; Visser-Vandewalle, V.; Dembek, T.A.; Meister, I.; Timmermann, L. Dysarthria in pallidal Deep Brain Stimulation in dystonia depends on the posterior location of active electrode contacts: A pilot study. Park. Relat. Disord. 2018, 47, 71-75. [CrossRef] [PubMed]

26. Bour, L.J.; Contarino, M.F.; Foncke, E.M.J.; De Bie, R.M.A.; Munckhof, P.V.D.; Speelman, J.D.; Schuurman, P.R. Long-term experience with intraoperative microrecording during DBS neurosurgery in STN and GPi. Acta Neurochir. 2010, 152, 2069-2077. [CrossRef] [PubMed]

27. Perez, J.; Gonzalez, V.; Cif, L.; Cyprien, F.; Chan-Seng, E.; Coubes, P. Rechargeable or Nonrechargeable deep brain stimulation in dystonia: A cost analysis. Neuromodulation Technol. Neural Interface 2017, 20, 243-247. [CrossRef]

28. Blahak, C.; Capelle, H.-H.; Baezner, H.; Kinfe, T.M.; Hennerici, M.G.; Krauss, J.K. Battery lifetime in pallidal deep brain stimulation for dystonia. Eur. J. Neurol. 2010, 18, 872-875. [CrossRef]

29. Meoni, S.; Fraix, V.; Castrioto, A.; Benabid, A.L.; Seigneuret, E.; Vercueil, L.; Pollak, P.; Krack, P.; Chevrier, E.; Chabardes, S.; et al. Pallidal deep brain stimulation for dystonia: A long term study. J. Neurol. Neurosurg. Psychiatry 2017, 88, 960-967. [CrossRef] [PubMed]

30. Skogseid, I.M.; Ramm-Pettersen, J.; Volkmann, J.; Kerty, E.; Dietrichs, E.; Røste, G.K. Good long-term efficacy of pallidal stimulation in cervical dystonia: A prospective, observer-blinded study. Eur. J. Neurol. 2011, 19, 610-615. [CrossRef]

31. Reese, R.; Fasano, A.; Knudsen, K.; Herzog, J.; Falk, D.; Mehdorn, H.M.; Deuschl, G.; Volkmann, J. Full Parkinsonian Triad Induced by Pallidal High-Frequency Stimulation in Cervical Dystonia. Mov. Disord. Clin. Pract. 2014, 2, 99-101. [CrossRef]

32. Zauber, S.E.; Watson, N.; Comella, C.L.; Bakay, R.A.E.; Metman, L.V. Stimulation-induced parkinsonism after posteroventral deep brain stimulation of the globus pallidus internus for craniocervical dystonia. J. Neurosurg. 2009, 110, 229-233. [CrossRef] [PubMed]

33. Lyons, K.E.; Pahwa, R. Effects of bilateral subthalamic nucleus stimulation on sleep, daytime sleepiness, and early morning dystonia in patients with Parkinson disease. J. Neurosurg. 2006, 104, 502-505. [CrossRef]

34. Kleiner-Fisman, G.; Liang, G.S.L.; Moberg, P.J.; Ruocco, A.C.; Hurtig, H.I.; Baltuch, G.H.; Jaggi, J.L.; Stern, M.B. Subthalamic nucleus deep brain stimulation for severe idiopathic dystonia: Impact on severity, neuropsychological status, and quality of life. J. Neurosurg. 2007, 107, 29-36. [CrossRef] [PubMed]

35. Ostrem, J.L.; Racine, C.A.; Glass, G.A.; Grace, J.K.; Volz, M.M.; Heath, S.L.; Starr, P.A. Subthalamic nucleus deep brain stimulation in primary cervical dystonia. Neurology 2011, 76, 870-878. [CrossRef]

36. Ostrem, J.L.; San Luciano, M.; Dodenhoff, K.A.; Ziman, N.; Markun, L.C.; Racine, C.A.; de Hemptinne, C.; Volz, M.M.; Heath, S.L.; Starr, P.A. Subthalamic nucleus deep brain stimulation in isolated dystonia: A 3-year follow-up study. Neurology 2017, 88, 25-35. [CrossRef]

37. Volkmann, J.; Benecke, R. Deep brain stimulation for dystonia: Patient selection and evaluation. Mov. Disord. 2002, 17, S112-S115. [CrossRef]

38. Brüggemann, N.; Kühn, A.; Schneider, S.A.; Kamm, C.; Wolters, A.; Krause, P.; Moro, E.; Steigerwald, F.; Wittstock, M.; Tronnier, V.; et al. Short- and long-term outcome of chronic pallidal neurostimulation in monogenic isolated dystonia. Neurology 2015, 84, 895-903. [CrossRef]

39. Panov, F.; Tagliati, M.; Ozelius, L.J.; Fuchs, T.; Gologorsky, Y.; Cheung, T.; Avshalumov, M.; Bressman, S.B.; Saunders-Pullman, R.; Weisz, D.; et al. Pallidal deep brain stimulation for DYT6 dystonia. J. Neurol. Neurosurg. Psychiatry 2011, 83, 182-187. [CrossRef]

40. Tisch, S.; Zrinzo, L.; Limousin, P.; Bhatia, K.P.; Quinn, N.; Ashkan, K.; Hariz, M. Effect of electrode contact location on clinical efficacy of pallidal deep brain stimulation in primary generalised dystonia. J. Neurol. Neurosurg. Psychiatry 2007, 78, 1314-1319. [CrossRef] [PubMed]

41. Reese, R.; Reich, M.M.; Falk, D.; Deuschl, G.; Mehdorn, H.M.; Volkmann, J. Intraoperative Thresholds for Capsular Stimulation Are Reliable for Chronic Pallidal Deep Brain Stimulation in Dystonia. Ster. Funct. Neurosurg. 2017, 95, 79-85. [CrossRef] [PubMed]

42. Berman, B.D.; Starr, P.A.; Marks, W.J., Jr.; Ostrem, J.L. Induction of Bradykinesia with pallidal deep brain stimulation in patients with cranial-cervical dystonia. Stereotact. Funct. Neurosurg. 2009, 87, 37-44. [CrossRef] [PubMed] 
43. Blahak, C.; Capelle, H.-H.; Baezner, H.; Kinfe, T.M.; Hennerici, M.G.; Krauss, J.K. Micrographia induced by pallidal DBS for segmental dystonia: A subtle sign of hypokinesia? J. Neural Transm. 2011, 118, 549-553. [CrossRef]

44. Schrader, C.; Capelle, H.H.; Kinfe, T.M.; Blahak, C.; Baezner, H.; Dressler, D.; Krauss, J. Pallidal deep brain stimulation may induce freezing of gait in patients with focal and segmental dystonia. Mov. Disord. 2010, 25 (Suppl. 1), S466-S467. 